\title{
miR-107 functions as a tumor suppressor in human esophageal squamous cell carcinoma and targets Cdc42
}

\author{
PRIYANKA SHARMA $^{1}$, NEERU SAINI ${ }^{2}$ and RINU SHARMA ${ }^{1}$ \\ ${ }^{1}$ University School of Biotechnology, Guru Gobind Singh Indraprastha University, New Delhi 110078; \\ ${ }^{2}$ Functional Genomics Unit, CSIR Institute of Genomics and Integrative Biology, Mall Road, Delhi 110007, India
}

Received October 26, 2016; Accepted December 28, 2016

DOI: 10.3892/or.2017.5546

\begin{abstract}
Previously, we reported significantly decreased expression of tissue and circulating miR-107 in esophageal cancer (EC). However, its role in esophageal tumorigenesis still remains elusive. Therefore, the aim of the present study was to analyze the role of miR-107 in esophageal squamous cell carcinoma (ESCC). The role of miR-107 in ESCC was evaluated using MTT assay, cell cycle analysis by flow cytometry, Annexin assay, colony formation assay and scratch assay. Overexpression of miR-107 in KYSE-410 cells suppressed cell proliferation at $72 \mathrm{~h}$ post-transfection $(\mathrm{P}=0.0001)$. Moreover, a significant increase in the G0/G1 population $(\mathrm{P}<0.001)$ and a significant decrease in the $\mathrm{G} 2 / \mathrm{M}(\mathrm{P}=0.032)$ population was also observed in the miR-107-treated cells as compared to the negative control (NC). Notably, miR-107 overexpression attenuated the colony formation potential of ESCC cells by $41.83 \%$ as compared to the NC $(\mathrm{P}=0.007)$. miR-107 mimic inhibited ESCC cell migration in a time-dependent manner, reducing the wound closure to only $50.41 \pm 7.23 \%$ at $72 \mathrm{~h}$ posttransfection $(\mathrm{P}=0.041)$. Further analysis by Matrigel invasion assay revealed a significant decrease in the migratory and invasive abilities of the KYSE-410 cells at $72 \mathrm{~h}$ post miR-107 transfection. qRT-PCR analysis showed decreased expression of one of the newly identified targets of miR-107, Cdc42, at the mRNA level. Further validation by western blotting confirmed a significant reduction in the identified target at the protein level. In addition, the relative luciferase activity of the reporter containing Cdc42 3'UTR was significantly decreased upon miR-107 co-transfection, indicating it to be a direct target of miR-107. Our results herein document that miR-107 functions as a tumor suppressor and inhibits the proliferation, migration and invasion of ESCC cells. Moreover, this is the first report showing Cdc42 as a downstream target of miR-107.
\end{abstract}

Correspondence to: Dr Rinu Sharma, University School of Biotechnology, Guru Gobind Singh Indraprastha University, Dwarka Sector-16C, New Delhi 110078, India

E-mail: rinusharma@gmail.com

Key words: esophageal squamous cell carcinoma, miR-107, Cdc42, cell proliferation, cell cycle arrest, luciferase reporter assay

\section{Introduction}

Esophageal cancer is a multifaceted disease with high incidence and mortality rates. Functional analysis of oncogenes or tumor suppressors will help in understanding the complex interactome and mechanism involved in its development and progression thereby opening new doors for novel therapeutics and cancer interventions. Recently, emerging evidence has shed light on the significant role of microRNAs in tumorigenesis by regulating key signaling cascades, such as cell cycle, apoptosis, epithelial-to-mesenchymal transition (EMT), cell migration and angiogenesis, thereby establishing a landmark in cancer biology. The expression of miRNAs in esophageal cancer was first studied by Guo et al (1) in a quest to identify differentially expressed miRNAs in esophageal cancer. Microarray analysis revealed a strong correlation between low expression of hsa-miR-103/107 and an extended overall survival period. miR-107 has also been implicated in hypoxic signaling and tumor angiogenesis in colon cancer. Its knockdown resulted in increased HIF-1 $\beta$ expression and hence an increased hypoxic signaling (2). He et al (3) demonstrated a tumor-suppressor role of miR-107 wherein, it suppressed glioma cell growth by directly targeting Spalt-like transcription factor 4 (SALL4), leading to the activation of FADD/caspase-8/caspase-3/-7 signaling pathway of cell apoptosis. Notably, miR-107 activated the ATR/Chk1 pathway and suppressed cervical cancer invasion by targeting myeloid cell leukemia 1 (MCL1) (4). Additionally, p53-induced microRNA-107 inhibited proliferation, migration and invasion of glioma cells by modulating the expression of cyclin-dependent kinase 6 (CDK6) and Notch-2 (5). It induced cell cycle G1 arrest and inhibited invasion by targeting CDK6, thereby inhibiting tumor progression in pancreatic, gastric, bladder and non-small cell lung cancer (NSCLC) (6-9). In one study, eukaryotic translation initiation factor 5 (EIF5) was found to be a direct target of miR-107 and a high miR-107 level induced cell cycle arrest at the $\mathrm{G} 2 / \mathrm{M}$ phase and retarded tumor growth in nude mice (10). miR-107 has also been shown to downregulate the expression of brain-derived neurotrophic factor (BDNF), C-C chemokine receptor type 5 (CCR5), granulin (GRN), cyclin-dependent kinase 8 (CDK8), let-7 and cyclin-dependent kinase 5 regulatory subunit 1 (CDK5R1)/p35 (11-16). Furthermore, Zhang et al (17) demonstrated that miR-107 plays a key role in cisplatin resistance by targeting the CDK8 protein in NSCLC 
Table I. Primers used for expression analysis of Cdc42 by qRT-PCR.

\begin{tabular}{lll} 
S.No. & Gene & \multicolumn{1}{c}{ Sequence } \\
\hline 1) & Cde42 & $\begin{array}{l}\text { Forward: 5'-TGACAGATTACGACCGCTGAGTT-3' } \\
\text { Reverse: 5'-GGAGTCTTTGGACAGTGGTGAG-3' }\end{array}$ \\
2) & 5S rRNA & Forward: 5'-GTCTACGGCCATACCACCCTG-3' \\
& & Reverse: 5'-AAAGCCTACAGCACCCGGTAT-3'
\end{tabular}

Product length (bp)

Reverse: 5'-AAAGCCTACAGCACCCGGTAT-3'

cell lines. According to a recent report by Datta et al (18) miR-107 functions as a candidate tumor-suppressor gene in head and neck squamous cell carcinoma (HNSCC) by downregulating protein kinase $\mathrm{C} \varepsilon(\mathrm{PKC} \varepsilon)$. Its treatment significantly blocked DNA replication, cell proliferation, colony formation and invasion in HNSCC cell lines. Moreover, lipid-based nanoparticle delivery of pre-miR-107 was found to inhibit the tumorigenicity of HNSCC (19). Zhang et al (20) suggested that the miR-25/miR-107-LATS2 axis may decrease the expression of LATS2, thereby affecting the growth and invasion of gastric cancer cells.

These observations suggest a possible role for miR-107 in the regulation of hypoxia, tumor progression and invasion (Fig. 1). Previously, we reported significantly decreased expression of miR-107 in neoplastic and preneoplastic esophageal tissues and esophageal cancer serum samples as compared to expression noted in normal subjects (21). However, its role in esophageal cancer has not yet been elucidated. Therefore, the aim of the present study was to analyze the function of miR-107 in esophageal tumorigenesis. Moreover, in our previous study, we predicted potential targets of miR-107 using Diana-miRGen that predicts targets using four widely used target prediction programs viz. PicTar, miRanda, TargetScanS, DIANA-microT. The targets were further screened on the basis of their Gene Ontology terms and $\mathrm{Cdc} 42$ was found to be one of the potential targets of miR-107. Notably, its expression was found to be inversely correlated with that of miR-107 in 66\% cases of esophageal cancer tissues (21). Therefore, we further aimed to ascertain whether $\mathrm{Cdc} 42$ is a direct downstream target of miR-107.

\section{Materials and methods}

Cell culture. Human esophageal squamous cell carcinoma cell line KYSE-410 was purchased from the European Collection of Authenticated Cell Cultures (ECACC), supplied by SigmaAldrich (Bangalore, India). The cell culture was maintained in Roswell Park Memorial Institute (RPMI)-1640 medium (Sigma-Aldrich) supplemented with fetal bovine serum (FBS; HiMedia Laboratories Pvt. Ltd., Mumbai, India) $10 \% \mathrm{v} / \mathrm{v}$, $100 \mathrm{U} / \mathrm{ml}$ of penicillin and $100 \mu \mathrm{g} / \mathrm{ml}$ of streptomycin (HiMedia Laboratories). The HEK-293T cell line was a kind gift by Dr Nimisha Sharma (GGSIPU, New Delhi). It was maintained in Dulbecco's modified Eagle's medium (DMEM; HiMedia Laboratories) supplemented with FBS $10 \%$ v/v, $100 \mathrm{U} / \mathrm{ml}$ of penicillin and $100 \mu \mathrm{g} / \mathrm{ml}$ of streptomycin. The cell lines were maintained in a humidified incubator with $5 \% \mathrm{CO}_{2}$ and $95 \%$ humidity in $25-\mathrm{cm}^{2}$ culture flasks (Corning Inc., Corning NY, USA) at $37^{\circ} \mathrm{C}$. The cells were passaged twice weekly to maintain an exponential growth phase. Other cell lines, SCC4, SCC9 and MCF-7, were a kind gift from Dr Shyam S. Chauhan (AIIMS, New Delhi, India) and Dr S. A. Raju Bagadi from the National Institute of Pathology (ICMR), New Delhi, India, respectively.

Transient transfection of miR-107 mimic using Lipofectamine 3000 . KYSE-410 cells were cultured in a $25-\mathrm{cm}^{2}$ culture flask to $\sim 80 \%$ density and collected by digestion and centrifugation,

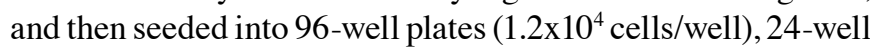
plate $\left(5 \times 10^{4}\right.$ cells/well) or 6 -well plate $\left(3 \times 10^{5}\right.$ cells/well $)$. hsa-miR-107 mimic (100 nM) (Ambion, Inc., Foster City, CA, USA) was transfected into the cells using Lipofectamine 3000 (Invitrogen, Carlsbad, CA, USA) and Opti-MEM medium (Invitrogen) according to the manufacturer's instructions. Negative control \#1 (Ambion) was used as the negative control.

miRNA extraction and quantitative RT-PCR. Total RNA was extracted using TRIzol (Invitrogen). First-strand cDNA synthesis was carried out using universal cDNA synthesis kit (Exiqon A/S, Vedbaek, Denmark) according to the manufacturer's protocol. qRT-PCR analysis of miR-107 was performed using SYBR-Green Master Mix (Exiqon A/S) and predesigned miR-107 specific LNA ${ }^{\mathrm{TM}}$ PCR primer sets (Exiqon A/S).

All PCR reactions were performed in aliquots of $20 \mu \mathrm{l}$ containing $8 \mu \mathrm{l}$ diluted cDNA template, $2 \mu \mathrm{l}$ of 10X Primer Mix and $10 \mu \mathrm{l}$ of 2X SYBR-Green Master Mix on Opticon2 real-time PCR system (Bio-Rad Laboratories, Hercules, CA, USA) (21). Thermal cycling parameters included a first denaturation step at $95^{\circ} \mathrm{C}$ for $10 \mathrm{~min}$, followed by 40 cycles of $95^{\circ} \mathrm{C}$ for $10 \mathrm{sec}$ and $60^{\circ} \mathrm{C}$ for $1 \mathrm{~min}$. The cycle threshold $(\mathrm{Ct})$ was recorded for each sample.

qRT-PCR of Cdc42 was carried out using gene-specific primers (Table I) and KAPA SYBR FAST real-time PCR kit (Kapa Biosystems, Inc., Wilmington, MA, USA) following the manufacturer's protocol. Its expression was analyzed at 48 and $72 \mathrm{~h}$ post miR-107 transfection using qRT-PCR. The expression of $\mathrm{Cdc} 42 \mathrm{mRNAs}$ in the mimic-treated cells was normalized to that of the cells treated with NC. Thus, $\Delta \Delta \mathrm{Ct}$ $=\Delta \mathrm{Ct}_{(\text {miR-107) }}-\Delta \mathrm{Ct}_{\text {(negative control) }}$.

A small RNA, 5S rRNA (Table I) was used as the endogenous control for data normalization. The $2^{-\Delta \Delta C T}$ method was used to calculate the fold-change where, $\mathrm{Ct}$ is the cycle number at which the fluorescence signal of the amplification plot passes a fixed threshold. $\Delta \mathrm{Ct}=\mathrm{Ct}_{(\mathrm{miR}-107)}-\mathrm{Ct}_{(5 \mathrm{~s})}, \Delta \Delta \mathrm{Ct}=\Delta \mathrm{Ct}_{(\mathrm{miR}-107)}$ $\Delta \mathrm{Ct}_{\text {(scrambled or untreated) }}$. A negative control without a template was run in parallel to assess the overall specificity of the reaction.

The qRT-PCR amplification products were analyzed by melting curve analysis and confirmed by agarose gel 


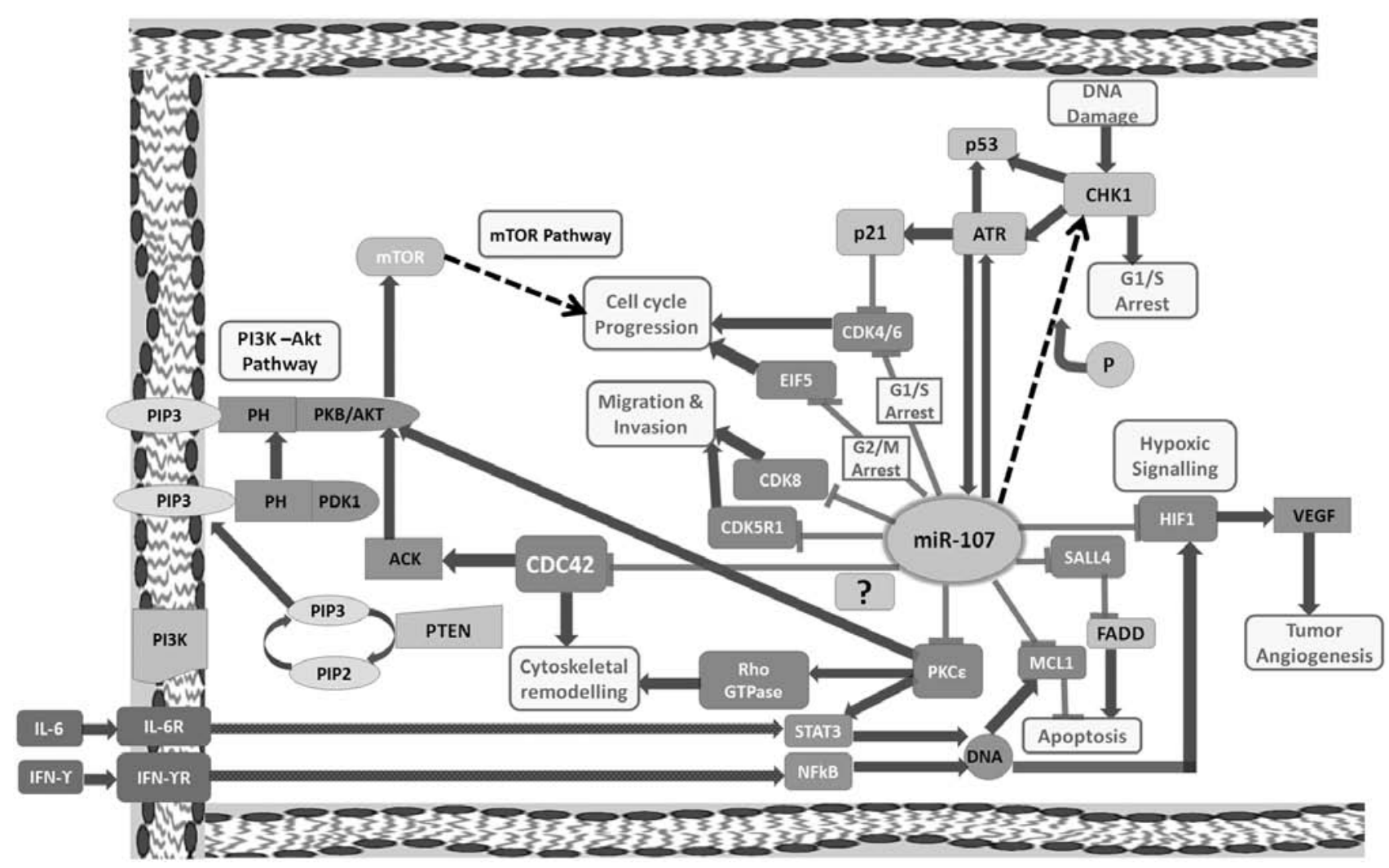

Figure 1. Schematic representation of miR-107-mRNA crosstalk in various types of cancers. ACK, activated Cdc42-associated kinase 1; ATR, ataxia telangiectasia and Rad3 related; CDC42, cell division cycle 42; CDK4, cyclin-dependent kinase 4; CDK6, cyclin-dependent kinase 6; CDK8, cyclin-dependent kinase 8; CDK5R1, cyclin-dependent kinase 5 regulatory subunit 1; CHK1, checkpoint kinase 1; EIF5, eukaryotic translation initiation factor-5; HIF1, hypoxiainducible factor 1; IFN $\gamma \mathrm{R}$, interferon $\gamma$ receptor 1; IL6R, interleukin 6 receptor; MCL1, myeloid cell leukemia 1; mTOR, mechanistic target of rapamycin; P, phosphorylation; PDK1, 3-phosphoinositide dependent protein kinase 1; PIP2, phosphatidylinositol 4,5-bisphosphate; PIP3, phosphatidylinositol (3,4,5)-trisphosphate; PKB, protein kinase B; PKC $\varepsilon$, protein kinase C $\varepsilon$; PTEN, phosphatase and tensin homolog; SALL4, spalt-like transcription factor 4; STAT3, signal transducer and activator of transcription 3; NFkB, nuclear factor $\kappa$ B; VEGF, vascular endothelial growth factor. CDK8, CDK4/6, EIF5, CDK5R1, HIF1, SALL4, MCL1, PKC $\varepsilon$ are the direct targets of miR-107. We aimed to ascertain whether CDC42 is a direct downstream target of miR-107.

electrophoresis. Single dissociation peak in the melting curve was indicative of specific amplification of the PCR product.

MTT assay. KYSE-410 cells were treated with $100 \mathrm{nM}$ miR-107 mimic and the MTT assay was performed at time intervals of 24, 48 and $72 \mathrm{~h}$ post transfection. A total of $20 \mu \mathrm{l}$ MTT (HiMedia Laboratories) at the concentration of $5 \mathrm{mg} / \mathrm{ml}$ was added to $1.2 \times 10^{4}$ cells suspended in $200 \mu 1 \mathrm{RPMI}-1640$ medium and incubated for $4 \mathrm{~h}$ at $37^{\circ} \mathrm{C}$ in dark. Then, $100 \mu \mathrm{l}$ dimethyl sulfoxide (DMSO; Amresco, Solon, OH, USA) was added to each well and was shaken for 20 min to dissolve the crystals. Blank samples were prepared using the same procedure. Absorbance was measured by using the SpectraMax spectrophotometer (Molecular Devices, Sunnyvale, CA, USA) at $570 \mathrm{~nm}$. Each reading was converted to the percentage of inhibition which was calculated as following: Inhibition rate $(\%)=(\mathrm{OD}$ value of the control group - OD value of the experimental group)/OD value of the control group x $100 \%$.

Colony formation assay. KYSE-410 cells were transfected with $100 \mathrm{nM}$ miR-107 mimic or NC. Twenty-four hours post transfection, the cells were trypsinized into single-cell suspension and added to a 6 -well plate at a density of $2 \times 10^{3}$ cells/well. The plates were then incubated at $37^{\circ} \mathrm{C}$ for 7 days and the medium was changed every two days. After 7 days the super- natant was discarded. The colonies were washed twice with phosphate-buffered saline (PBS) and fixed with pre-chilled methanol for $20 \mathrm{~min}$. The colonies were then stained with crystal violet (HiMedia Laboratories) for $20 \mathrm{~min}$. Images of the stained tumor cell colonies were then recorded with a digital camera and colonies containing at least 50 cells were quantified using imaging analysis tool ImageJ.

Cell cycle analysis. Cell cycle analysis was performed by flow cytometry on FACSCalibur (BD Biosciences, San Jose, CA, USA). Briefly, cells were fixed in $70 \%$ ethanol overnight at $-20^{\circ} \mathrm{C}$. For fixing mimic/NC-treated and untreated cells were harvested and resuspended in $300 \mu \mathrm{l}$ of PBS and then $700 \mu \mathrm{l}$ of chilled $100 \%$ ethanol was added. After fixing, the cells were stained with propidium iodide $(10 \mu \mathrm{g} / \mathrm{ml})$ and RNaseA $(100 \mu \mathrm{g} / \mathrm{ml})$. The stained cells were then subjected to flow cytometry and data was acquired. Analysis was carried out using BD CellQuest (BD Biosciences).

Apoptosis assay. Effect of miR-107 overexpression on apoptosis of the EC cells was analyzed by flow cytometry using the Annexin V/7-AAD apoptosis detection kit (BD Biosciences) on LSRII (Becton-Dickinson). Briefly, $2.5 \times 10^{5}$ cells were treated with $100 \mathrm{nM}$ miR-107 or NC and the cells were harvested at $72 \mathrm{~h}$ post-transfection. The cell pellet was washed twice with 
Table II. Primers used for preparing Cdc42 pMIR-REPORT construct.

\begin{tabular}{llc}
\hline & \multicolumn{1}{c}{ Sequence } & Position \\
\hline Cdc42 Var1/Var2 (3'UTR) forward primer & 5'-GCCACGCGTGCCTATCACTCCAGAGACTGC-3' & 571-591 \\
Cdc42 Var1 (3'UTR) reverse primer & 5'-CGCAAGCTTGAGCACCAGATGGGGAACAT-3' & $1308-1327$ \\
Cdc42 Var2 (3'UTR) reverse primer & 5'-CGCAAGCTTGAGGACATTCTTAAAGCCAGACC-3' & $1021-1043$ \\
\hline
\end{tabular}

Table III. Primers used for preparing CDK6 pMIR-REPORT construct.

\begin{tabular}{lcc}
\hline & Sequence & Position \\
\hline CDK6 (3'UTR) forward primer & 5'-CTTACGCGTTGTCTTCTGGACAGGCTCTG-3' & $1511-1531$ \\
CDK6 (3'UTR) reverse primer & 5'-CGCAAGCTTAGAATCTCTCACATACACAC-3' & $1831-1850$ \\
\hline
\end{tabular}

cold PBS and resuspended in $100 \mu 1$ of $1 \mathrm{X}$ binding buffer. To the cell suspension, $5 \mu \mathrm{l}$ of PE Annexin $\mathrm{V}$ and $5 \mu \mathrm{l}$ of 7-AAD were added. The cells were gently vortexed and incubated for $15 \mathrm{~min}$ at room temperature $\left(25^{\circ} \mathrm{C}\right)$ in the dark. After incubation, $400 \mu \mathrm{l}$ of $1 \mathrm{X}$ binding buffer was added to each tube and analyzed by flow cytometry using FACSDiva version 8.1.3 (BD Biosciences). The untreated population was used to define the basal level of apoptotic or dead cells.

Wound healing assay. KYSE-410 cells ( $3 \times 10^{5}$ cells/well) were seeded in a 6-well plate overnight to obtain $90 \%$ confluency. At $24 \mathrm{~h}$ post-transfection with $100 \mathrm{nM}$ miRNA mimic, a scratch was made through the center of each well using a $1000-\mu 1$ pipette tip, creating an open 'wound' that was clear of cells. The dislodged cells were removed by two washes with PBS, fresh media was added and plates were cultured. Migration into the open area was observed at 24, 48 and $72 \mathrm{~h}$ post-scratching using ImageJ software. The percentage of wound closure was calculated as percentage of wound area covered at a given time compared to the initial wound surface.

Transwell-Matrigel invasion assay. Transwell-Matrigel invasion assay was performed at 48 and $72 \mathrm{~h}$ after miR-107 transfection, using Transwell inserts (Corning Inc.) coated with Matrigel (BD Biosciences). Cells $\left(4 \times 10^{4}\right)$ in PBS were seeded to the upper chamber and RPMI medium containing $20 \%$ FBS was added to the lower chamber as the chemoattractant. After incubation at $37^{\circ} \mathrm{C}$ for $24 \mathrm{~h}$, the non-invaded cells were removed from the upper chamber using a cotton swab. The invaded cells were then fixed in methanol, stained with DAPI and photographed in at least five fields using an inverted fluorescence microscope (Nikon, Tokyo, Japan) under a 10X objective. The cells were counted using Nikon imaging software NIS-Elements BR Ver4.40.00.

Western blot analysis. The cells were washed twice with ice cold PBS and scraped with RIPA buffer (Invitrogen) supplemented with a protease inhibitor cocktail (Invitrogen). Cells were further lysed with two pulses of sonication for $9 \mathrm{sec}$ at $39 \%$. The protein concentration was measured using the Bradford assay (Bio-Rad Laboratories). Equivalent quantities
(70 $\mu \mathrm{g})$ of protein were separated by $15 \%$ sodium dodecyl sulfate polyacrylamide gel electrophoresis (SDS-PAGE) and transferred to polyvinylidene fluoride microporous (PVDF) membranes (Microdevices, Inc., New Delhi, India). The membranes were blocked with $5 \%$ non-fat milk in PBS overnight at $4^{\circ} \mathrm{C}$. Membranes were then incubated for $1 \mathrm{~h}$ with primary antibodies of Cdc42 and GAPDH (Santa Cruz Biotechnology, Santa Cruz, CA, USA) at dilutions of 1:50 and 1:200, respectively. The membranes were washed 3 times in $0.2 \%$ PBS-Tween followed by one wash with PBS and incubated with the horseradish peroxidase (HRP)-conjugated anti-rabbit secondary antibody for $1 \mathrm{~h}$. After washing, bound secondary antibody was detected using an enhanced chemiluminescence (ECL) system (Pierce Biotechnology Rockford, IL, USA). Western blot results were analyzed quantitatively by ImageJ software.

Cdc42-3'UTR reporter construct. Cdc42 has three splice variants. Splice variant 1 (NM_001791) and splice variant 3 have a similar 3'UTR while splice variant 1 and splice variant 2 (NM_044472) have a similar 5'UTR and coding sequence but differ at 3'UTR. RNA hybrid was used to calculate minimum free energy of hybridization for target sites present at the 3'UTR. Cdc42 variant 1 has three target sites at positions 714 $(\mathrm{MFE}=-26 \mathrm{Kcal} / \mathrm{mol}), 754(\mathrm{MFE}=-24.5 \mathrm{Kcal} / \mathrm{mol})$ and 1087 (MFE $=-24 \mathrm{Kcal} / \mathrm{mol}$ ) (Fig. 2A). Target sites are present at positions 722,756 and 927 in variant 2 with MFE of -21.126, -22.526 and $-25.526 \mathrm{Kcal} / \mathrm{mol}$ (Fig. $2 \mathrm{~B}$ and C). Therefore, the 3'UTRs of variant 1 (757 bp) and variant 2 (473 bp) containing the predicted miR-107 target sites were amplified and cloned into the pMIR-REPORT luciferase vector (Promega) between the Mlu1 and HindIII restriction sites, downstream to the luciferase reporter gene using primers as described in Table II.

CDK6-3'UTR-pMIR-REPORT construct. To generate the 3'UTR-REPORT construct, a 340-bp region of CDK6 3'UTR (NM_001259.6) containing the predicted miR-107 binding site (Fig. 2D) was amplified and cloned into the pMIR-REPORT luciferase vector (Promega) between the Mlu1 and HindIII restriction sites, downstream to the luciferase reporter gene using the primers as described in Table III. 


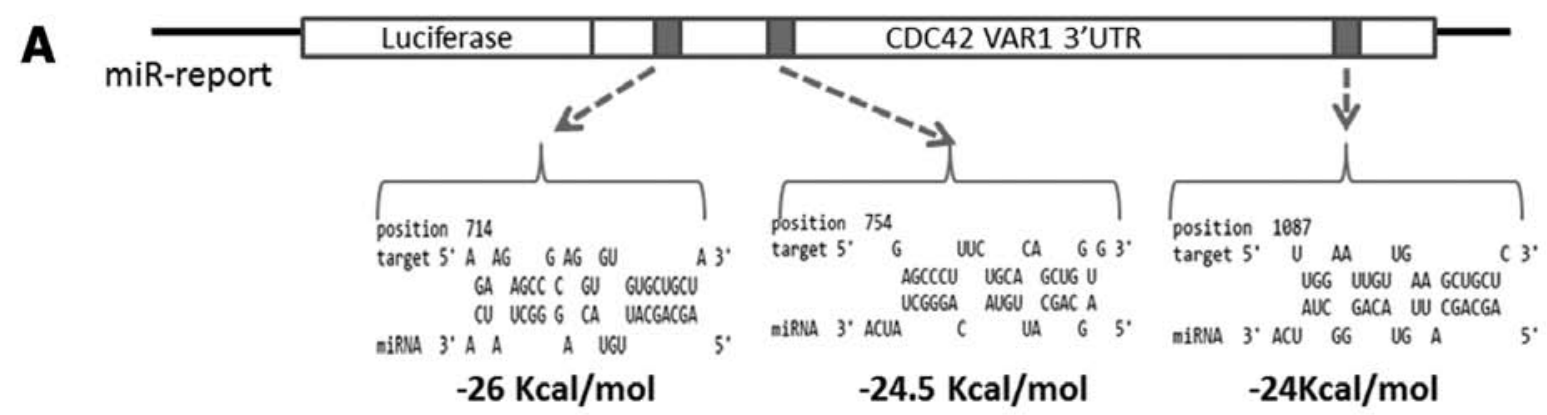

B
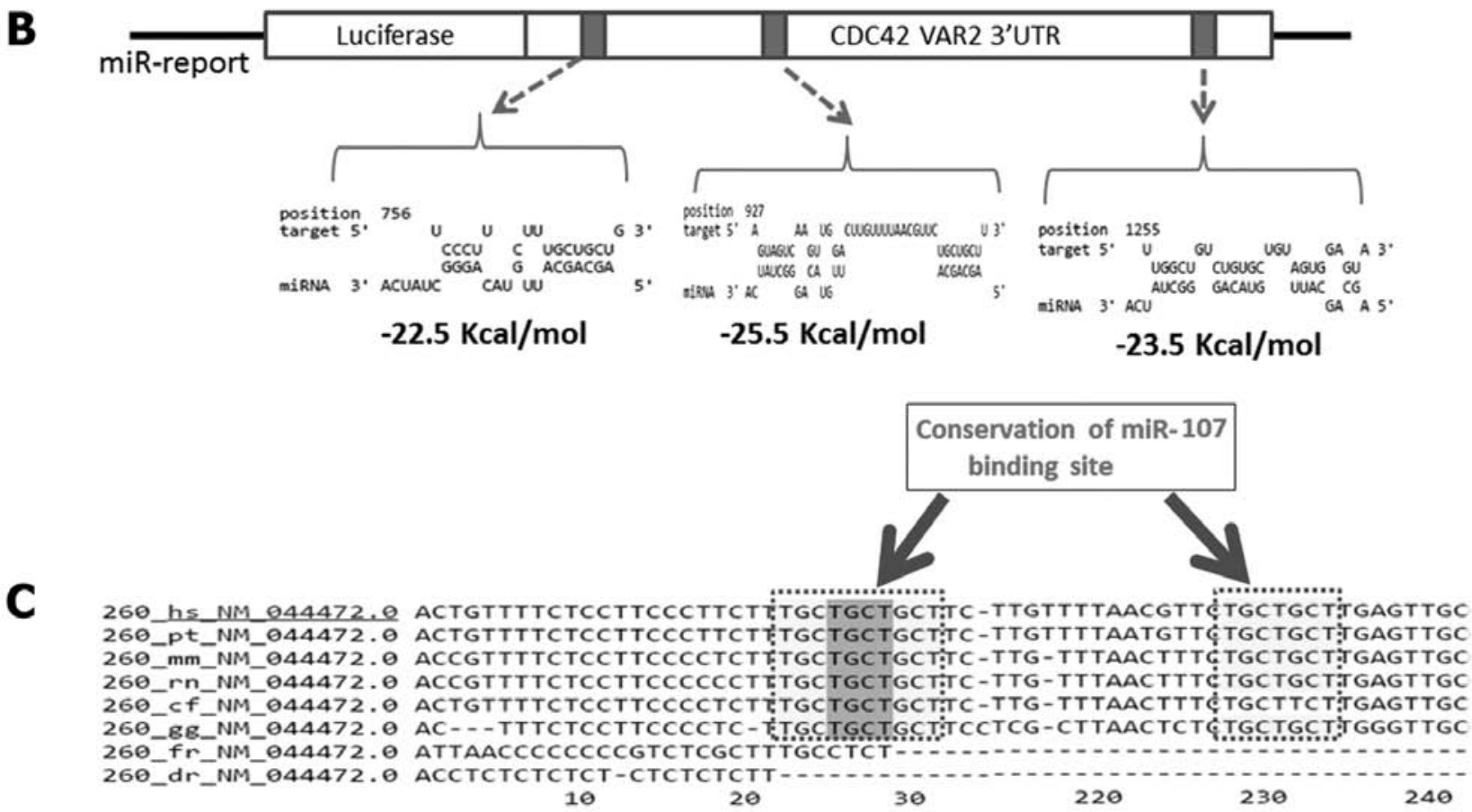

D

\author{
3' acuaUCGG-GACAUGU---UACGACGa 5 ' hsa-miR-107 \\ III: 111 II : 111111 \\ 261:5' gagaagCUGCUGACCAAUUGUGCUGCC $3^{\prime}$ CDK6 \\ 3' acuAUCGgGaCAUGUUACGACGa 5 ' hsa-miR-107 \\ $11|1: 11| 1111111$ \\ 297:5' UuCUAACCUUG---AAUGCUGCC 3 ' CDK6
}

Figure 2. Potential binding site of miR-107 in the CDC42 3'UTR. (A) The potential binding site for miR-107 in $3^{\prime}$ UTR of Cdc42 variant 1 mRNA. (B) The potential binding site for miR-107 in the $3^{\prime}$ UTR of Cdc42 variant 2 mRNA. (C) Conservation of the miR-107 binding site. (D) The potential binding site for miR-107 in the $3^{\prime}$ UTR of CDK6 mRNA.

Luciferase reporter assay. Post-transcriptional inhibition of the luciferase reporter gene by miR-107 was assayed in HEK-293T cells. Briefly,HEK-293T cells were seeded into 24 -well plates and cultured until $80 \%$ confluent. The cells were then co-transfected with either miR-107 mimic or negative control at a $100 \mathrm{nM}$ final concentration and with $100 \mathrm{ng}$ of pMIR-REPORT construct containing Cdc42 3'UTR along with 10 ng Renilla luciferase vector using Lipofectamine 3000 transfection reagent according to the manufacturer's recommendations (Invitrogen). Relative firefly luciferase activity, which was normalized with Renilla luciferase, was measured using a Dual-luciferase reporter gene assay system (Promega) and the results were plotted as the percentage of change over the respective control.
Statistical analysis. All experiments were repeated at least three times and the Student's t-test was used to analyze the statistical significance between two groups while one-way ANOVA was used to determine the significance of differences among multiple groups. $\mathrm{P}<0.05$ was considered to indicate a statistically significant difference. When the difference between the groups was found to be statistically significant, then multiple comparisons were performed between treatments within each time period by Tukey's HSD test. All the statistical analysis were performed using GraphPad Prism software version 6.00 (GraphPad Software, Inc., San Diego, CA, USA) and SPSS software 16.0 (SPSS, Inc., Chicago, IL, USA). 

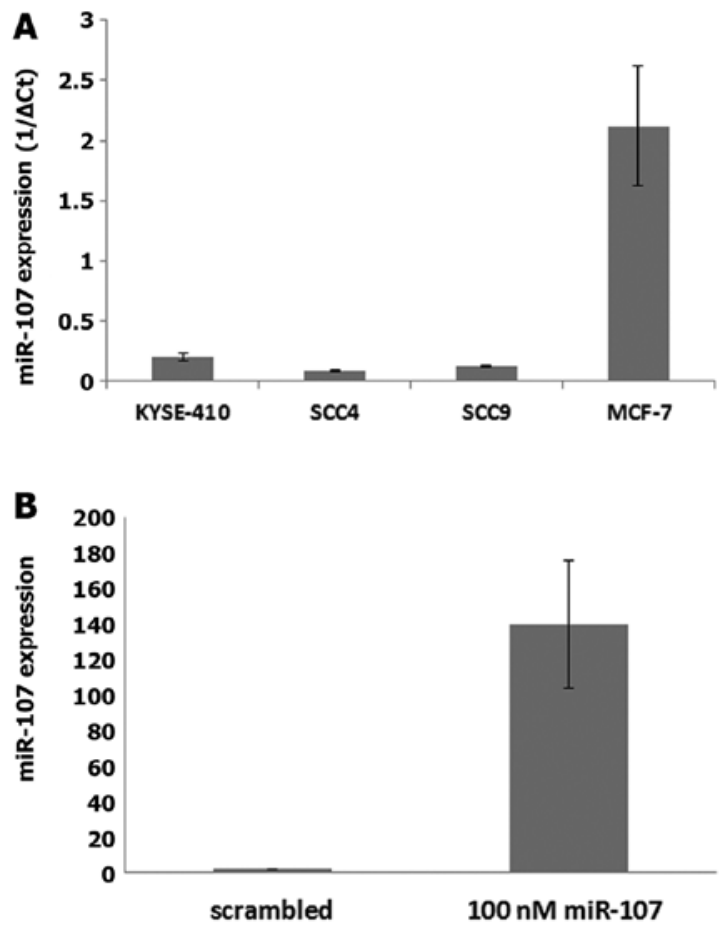

Figure 3. Expression of miR-107 in different cell lines. (A) Histogram showing the relative expression of miR-107 in different cell lines (high value of $1 / \Delta C T$ represents high miRNA expression). (B) Histogram showing fold-change in miR-107 expression at $48 \mathrm{~h}$ after transfection of the KYSE-410 cells.

\section{Results}

miR-107 expression in the cell lines. The expression of miR-107 was assessed in four different cell lines: esophageal squamous cell carcinoma (KYSE-410), tongue squamous cell carcinoma (SCC-4 and SCC-9) and breast adenocarcinoma (MCF-7) cell lines. The results showed that the level of miR-107 was relatively lower in the KYSE-410, SCC-4 and SCC-9 cell lines as compared to the level noted in the MCF-7 cells (Fig. 3A).

Transfection efficiency. Real-time PCR analysis revealed an increase in miR-107 expression by 160 -fold at $48 \mathrm{~h}$ post miR-107 mimic transfection in the KYSE-410 cells as compared to the cells treated with negative control (NC) indicating that miR-107 was successfully transfected (Fig. 3B).

Overexpression of miR-107 suppresses cell proliferation of esophageal cancer cells. Compared with the control group, cell proliferation in the miR-107-treated group was inhibited in a dose- and time-dependent manner. Cell proliferation was significantly $(\mathrm{P}=0.0001)$ inhibited when cells were treated with $100 \mathrm{nM}$ miR-107 mimic for $72 \mathrm{~h}$ with the inhibition rate of $34.079 \%$ (Fig. 4). Notably, Tukey's multiple comparisons test revealed that cell proliferation of KYSE-410 cells was significantly inhibited at 24 and $72 \mathrm{~h}$ after transfection with $100 \mathrm{nM}$ miR-107 mimic as compared to the NC. Whereas, at $48 \mathrm{~h}$ the difference in cell proliferation of the two groups was not found to be statistically significant.

Overexpression of miR-107 causes cell cycle arrest in $G 1 / \mathrm{S}$ phase. DNA content analysis by flow cytometry showed a

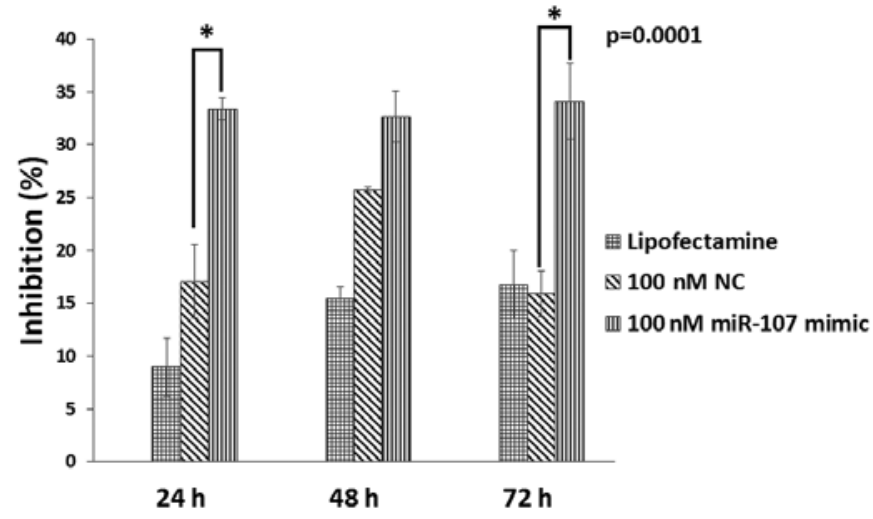

Figure 4. Histogram representing the percentage of inhibition in cell proliferation after transfection of $100 \mathrm{nM}$ miR-107 mimic at 24,48 and $72 \mathrm{~h}$ in the KYSE-410 cells. NC, negative control.

significantly $(\mathrm{P}<0.001)$ increased percentage of KYSE-410 cells in the G1 phase (from $64.35 \pm 1.16$ to $79.91 \pm 0.77 \%$ ) of the cell cycle, at $48 \mathrm{~h}$ post-miR-107 transfection as compared to the NC-treated cells (Fig. 5A and B). While a substantial decrease in $\mathrm{S}$ phase (from $12.19 \pm 2.48$ to $7.4 \pm 1.3 \%$ ) and a significant decrease in $\mathrm{G} 2 / \mathrm{M}$ phase (from $21.47 \pm 2.56$ to $11.45 \pm 0.98 \%$, $\mathrm{P}=0.032$ ) populations was observed in the miR-107-treated cells as compared to the NC.

At $72 \mathrm{~h}$ after transfection, the percentage of cells in the G1 phase was significantly $(\mathrm{P}=0.044)$ increased from $67.99 \pm 1.89$ to $73.87 \pm 1.23 \%$ when transfected with $100 \mathrm{nM}$ miR-107 as compared to the NC-transfected cells (Fig. 5C). A significant decrease in the $\mathrm{G} 2 / \mathrm{M}(\mathrm{P}=0.024)$ cell population was also observed in the miR-107-treated cells as compared to the NC-treated cells.

Effect of miR-107 overexpression on the apoptosis of ESCC cells. In addition to the cell cycle distribution, we also analyzed the effect of miR-107 overexpression on the apoptosis of ESCC cells. An increase in the percentage of early apoptotic cells was observed at $72 \mathrm{~h}$ post transfection in the miR-107-transfected group (from $9.1 \pm 1.3$ to $14.05 \pm 2.15 \%$ ) as compared to the $\mathrm{NC}$ group (Fig. 5D).

Overexpression of miR-107 inhibits ESCC colony formation. We also investigated the role of miR-107 on ESCC clonogenic survival, and the results demonstrated a significant $(\mathrm{P}<0.001)$ decrease in the clonogenic survival of the miR-107-treated cells (colony count, 265 \pm 22.9 ), as compared to the NC-treated cells (colony count, 529 \pm 10.17 ) and untreated ESCC cells (colony count, 637 \pm 27.79 ) (Fig. 6A). When normalized to untreated cells, the colony formation efficiency of the miR-107-treated cells was significantly reduced to $41.44 \pm 4.23 \%$ as compared to the NC-treated cells where the colony formation efficiency was $83.27 \pm 3.51 \%$ (Fig. 6B).

Increased expression of miR-107 suppresses wound healing in the ESCC cells. Scratch assay was used to detect the effect of miR-107 on the migration of KYSE-410 cells. Wound closure was evaluated at different time-points, 24, 48 and $72 \mathrm{~h}$ post scratching. Seventy-two hours were required for the wound to completely close in the untreated cells. At $72 \mathrm{~h}$ post miR-107 
A

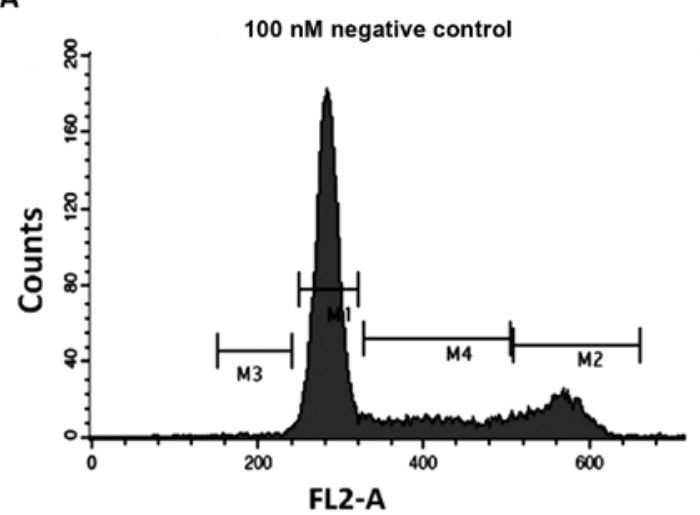

B

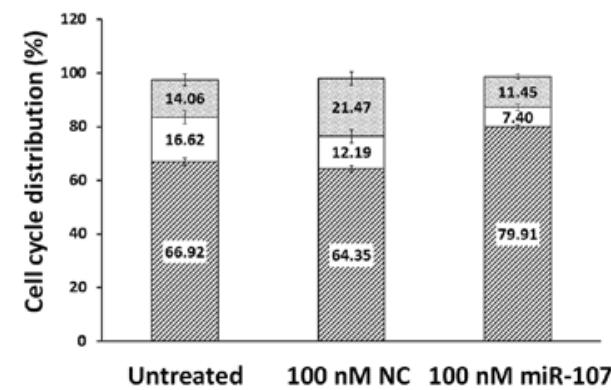

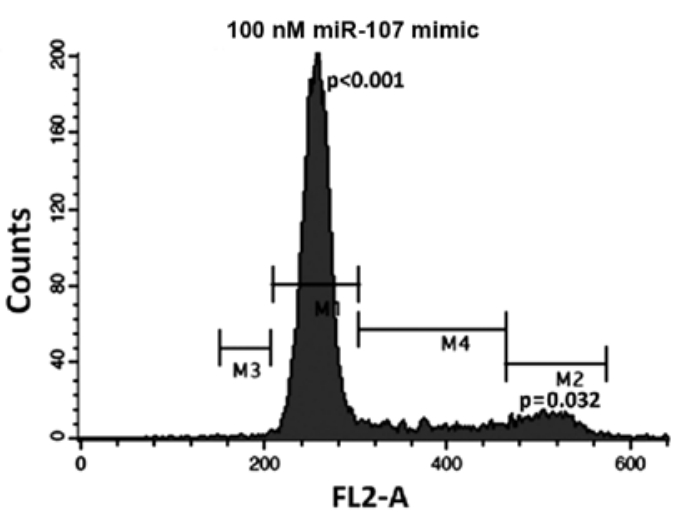

C

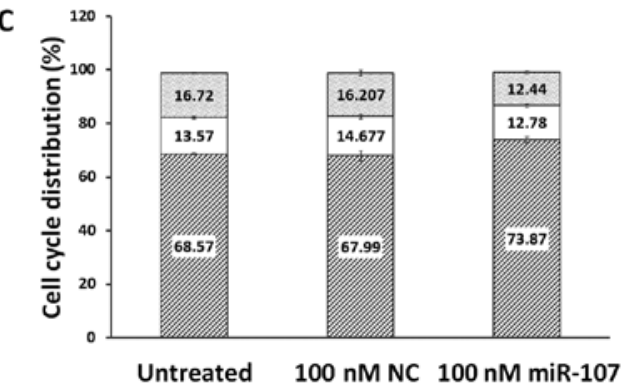

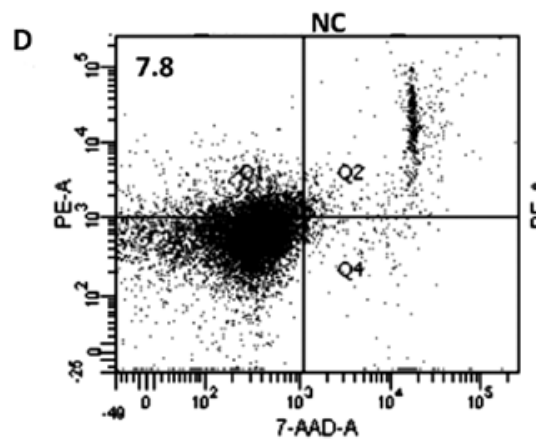
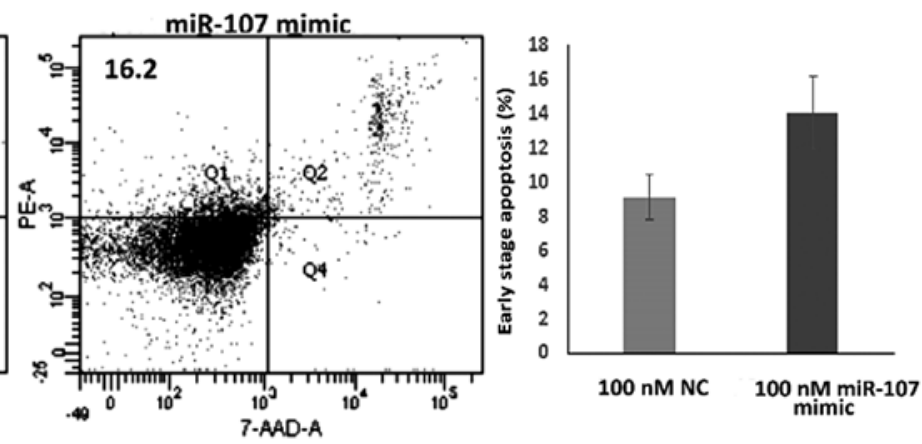

Figure 5. Overexpression of miR-107 induces G1/S arrest in KYSE-410 cells. (A) Flow cytometric results showing an increase in the G0/G1 cell population and a decrease in S phase and G2/M phase populations in the miR-107-treated KYSE-410 cells as compared to the negative control (NC) group after $48 \mathrm{~h}$ of miR-107 overexpression. (B and C) Histograms reflect cell cycle distribution after 48 and $72 \mathrm{~h}$ post-transfection, respectively. (D) Effect of miR-107 overexpression on the apoptosis of ESCC cells.
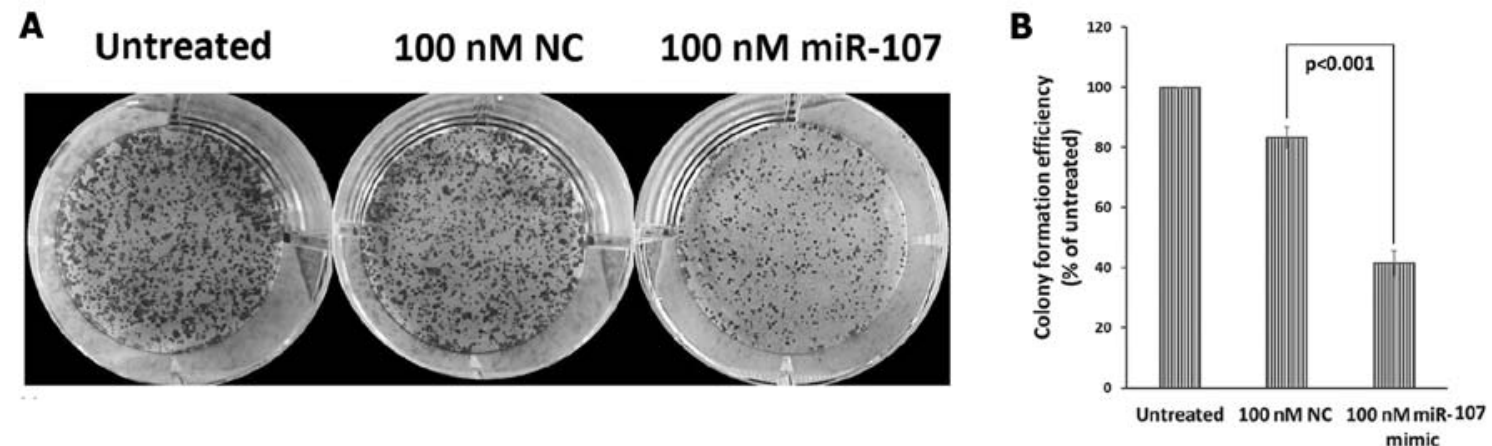

Figure 6. Effect of miR-107 on the colony formation potential of ESCC cells. (A) Representative images of colony formation assay after transfection of miR-107 or negative control (NC) for 7 days. (B) Histogram showing relative colony formation efficiency in the miR-107- or NC-treated group when normalized to the untreated group.

transfection, a significant difference was found between the groups $(\mathrm{P}=0.023)$. Tukey's multiple comparisons test revealed that cell migration was significantly inhibited at $72 \mathrm{~h}$ after transfection of $100 \mathrm{nM}$ miR-107 as compared to the NC group $(\mathrm{P}=0.041)$. miR-107 treatment inhibited cell migration in a time-dependent manner reducing the wound closure to only 

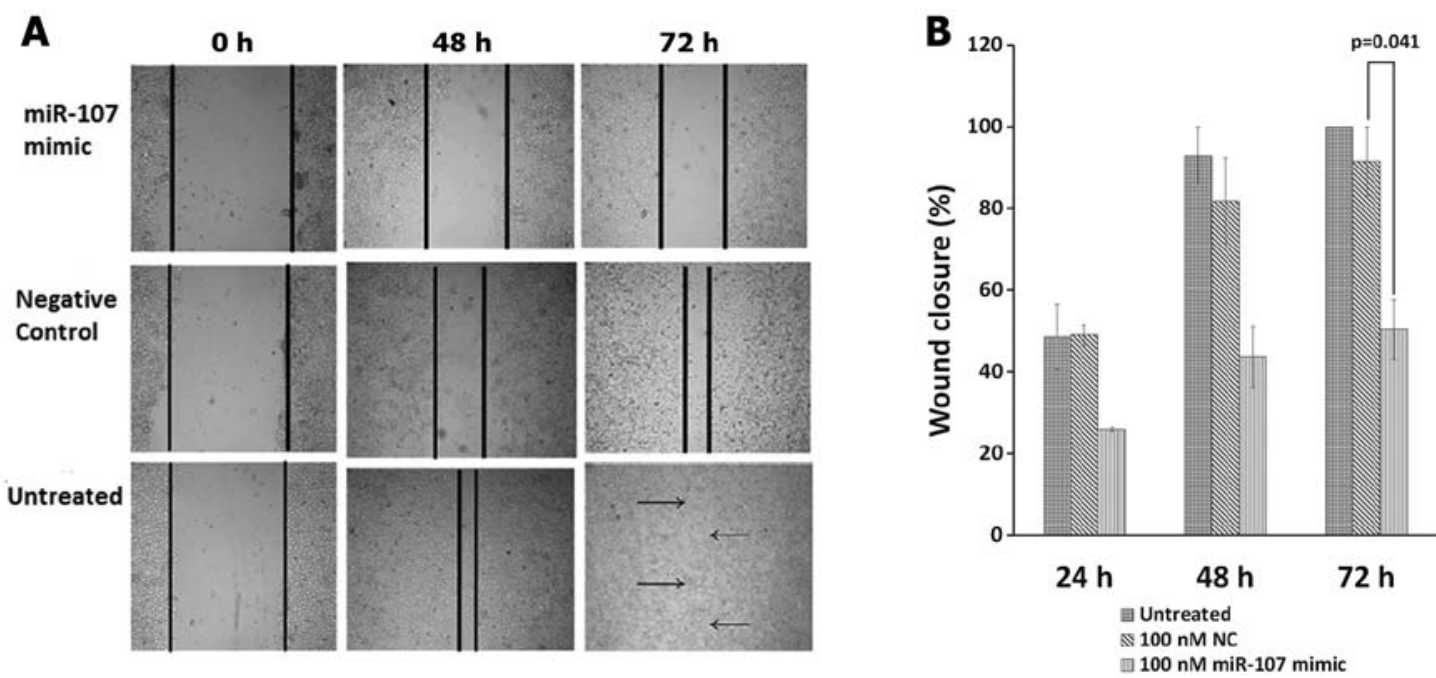

Figure 7. miR-107 inhibits the wound healing of KYSE-410 cells. (A) Representative images of the wound healing assay at 24, 48 and $72 \mathrm{~h}$ post miR-107 transfection. (B) Histogram showing the percentage of wound closure in the miR-107- or negative control (NC)-treated and untreated groups. The scratch healed up to $91.535 \pm 8.465 \%$ in the NC group after $72 \mathrm{~h}$, while the scratch in miR-107-transfected group healed up to only $50.41 \pm 7.23 \%$.

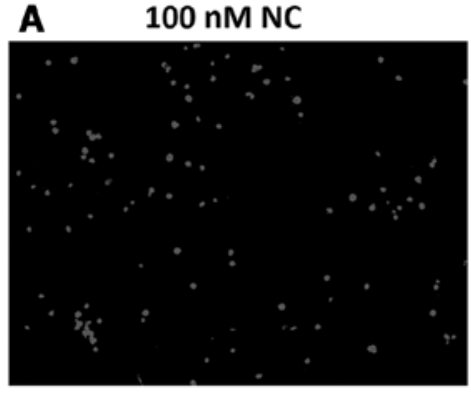

C

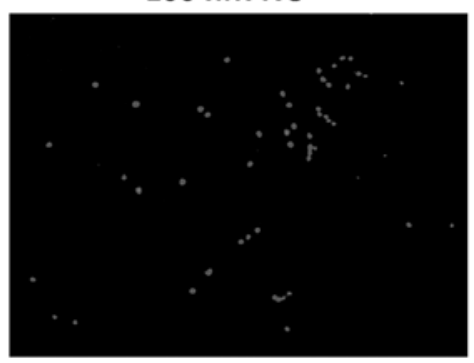

$100 \mathrm{nM}$ miR-107 mimic

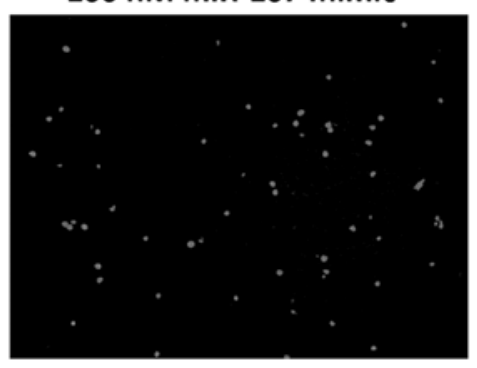

$100 \mathrm{nM}$ miR-107 mimic

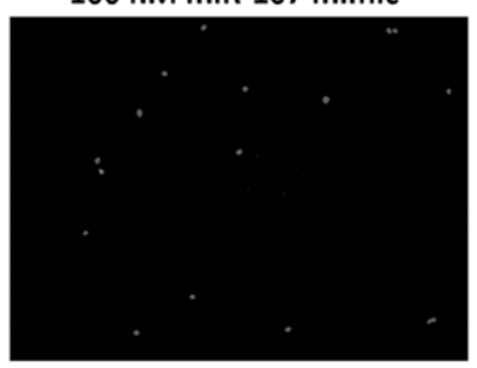

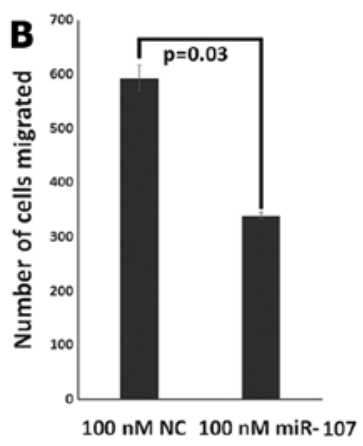

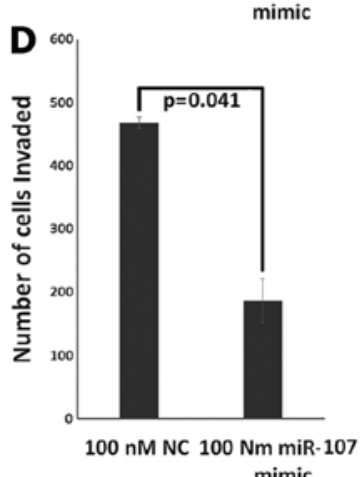

Figure 8. Effect of miR-107 on the migration and invasion potential of ESCC cells. (A) Representative images of Transwell migration assay showing the number of cells migrated in the miR-107 or negative (NC)-transfected group at $72 \mathrm{~h}$ post transfection. (B) Histogram showing the number of cells migrated through the chamber in the $100 \mathrm{nM}$ miR-107 mimic- or NC-treated groups. (C) Representative images of Transwell-Matrigel invasion assay showing the number of cells that invaded in the miR-107- or NC-transfected groups at $72 \mathrm{~h}$ post transfection. (D) Histogram showing the number of cells that invaded through the Matrigel in the $100 \mathrm{nM}$ miR-107 mimic- or NC-treated groups.

$50.41 \pm 7.23 \%$ at $72 \mathrm{~h}$ as compared to the $\mathrm{NC}$ where the scratch wound healed up to $91.535 \pm 8.465 \%$ (Fig. 7A and B). However, at 24 or $48 \mathrm{~h}$, there was no significant difference in cell migration of the two groups.

Overexpression of miR -107 results in decreased migration and invasion potential of the ESCC cells. We further evaluated the effect of miR-107 on the migration and invasion abilities of the KYSE-410 cells using Transwell assay. Overexpression of
miR-107 resulted in significantly decreased migratory ability of the KYSE-410 cells at $72 \mathrm{~h}$ post transfection $(\mathrm{P}=0.03)$ (Fig. 8A). The number of KYSE-410 cells that had migrated through the chamber was $338 \pm 6$ and $592 \pm 23$ in the miR-107 mimic-treated and NC-treated group, respectively (Fig. 8B). Notably, the invasive ability of the KYSE-410 cells was significantly decreased at $72 \mathrm{~h}$ post miR-107 transfection as compared to the NC group ( $\mathrm{P}=0.041)$ (Fig. $8 \mathrm{C}$ ). The number of invasive cells was $468 \pm 9$ in the NC-treated group as compared to the 
A CDC42 expression after miR-107 transfection

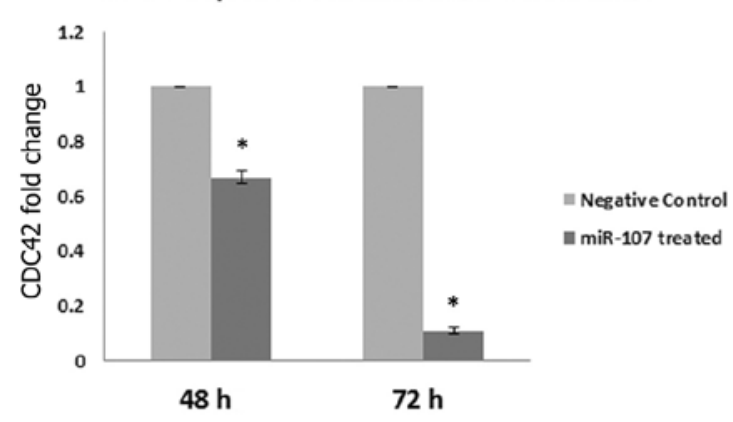

C

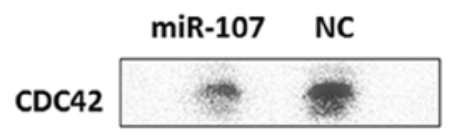

GAPDH

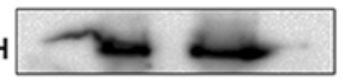

B

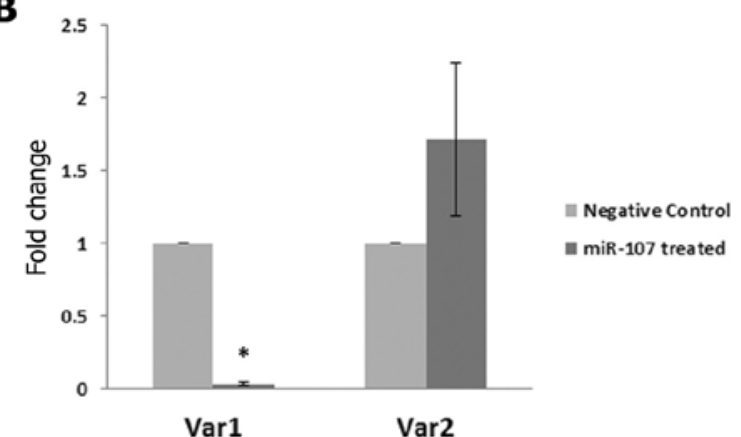

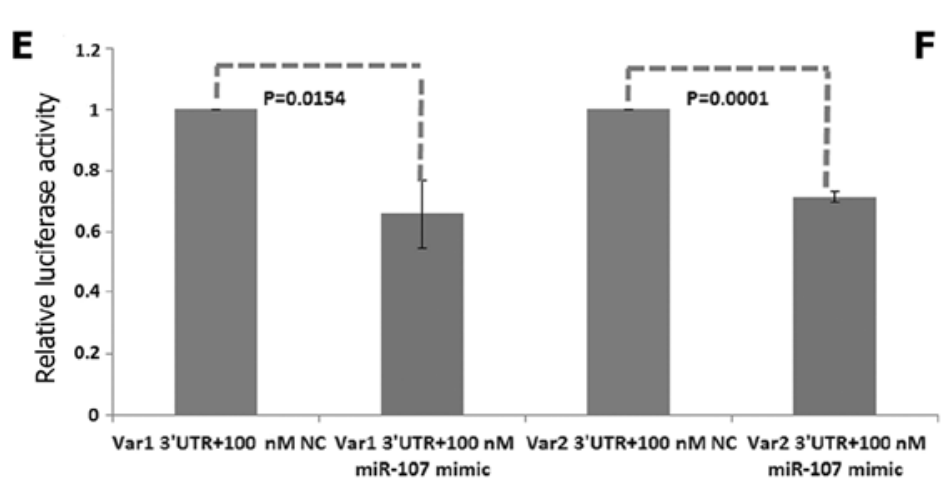

D

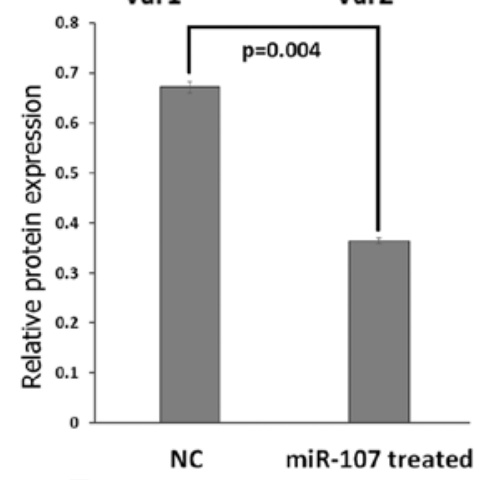

$\mathbf{F}$

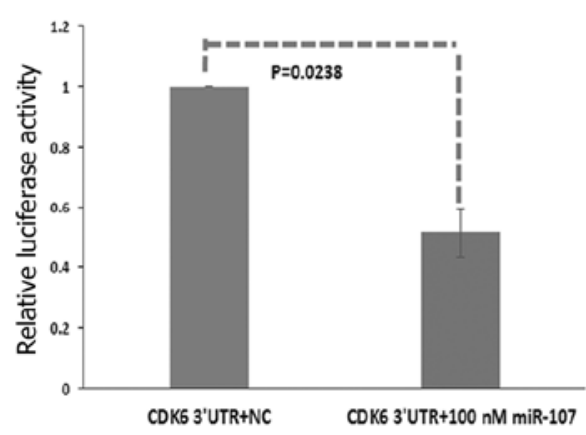

Figure 9. Overexpression of miR-107 results in decreased expression of Cdc42. (A) Histogram showing fold-change in expression of Cdc42 at 48 and $72 \mathrm{~h}$ after transfection of the miR-107 mimic. (B) Histogram showing fold-change in expression of Cdc42 variant 1 and Cdc 42 variant 2 at $72 \mathrm{~h}$ after transfection of miR-107 mimic. (C) Western blot analysis. Effect of miR-107 overexpression on Cdc42 protein levels in the KYSE-410 cells. (D) The relative expression of Cdc 42 protein was calculated as band intensity of Cdc42/band intensity of GAPDH. (E) The relative luciferase activity in cells co-transfected with miR-107 mimic and Cdc42 3'-UTR in the HEK293T cell line as compared to the NC. (F) The relative luciferase activity in cells co-transfected with miR-107 mimic and CDK6 3'-UTR in the HEK293T cell line as compared to the NC. NC, negative control; UTR, untranslated region.

mimic-treated group where only $187 \pm 34$ cells could invade the chamber (Fig. 8D). Out of all the migrated cells $55 \pm 9 \%$ of the cells invaded in the mimic-treated group while $79 \pm 1.5 \%$ of the cells invaded in the NC-treated group suggesting relatively weaker invasive ability of the KYSE-410 cells after miR-107 overexpression. However, at $48 \mathrm{~h}$ post miR-107 transfection, there was no significant difference in migration or invasion potential of the two groups (data not shown).

miR-107 overexpression results in decreased expression of Cdc42 at the mRNA level. Notably, overexpression of miR-107 resulted in significantly decreased expression of $\mathrm{Cdc} 42$ at the mRNA level in the miR-107-treated cells (fold-change, 0.67 at $48 \mathrm{~h}, \mathrm{P}=0.0074$ and 0.11 -fold at $72 \mathrm{~h}, \mathrm{P}=0.0016$ ) as compared to the NC-treated cells, suggesting that miR-107 may suppress the expression of $\mathrm{Cdc} 42$ at the transcriptional level (Fig. 9A).

Furthermore, the expression of $\mathrm{Cdc} 42$ variants was analysed at 48 and $72 \mathrm{~h}$ after transfection of the miR-107 mimic.
Notably, overexpression of miR-107 resulted in significantly $(\mathrm{P}=0.0041)$ decreased expression of $\mathrm{Cdc} 42$ variant 1 at the mRNA level in the miR-107-treated cells (fold-change, 0.033) as compared to the NC-treated cells at $72 \mathrm{~h}$ post-transfection, suggesting that miR-107 may regulate the expression of Cdc 42 variant 1 at the transcriptional level (Fig. 9B). However, no decrease in expression of $\mathrm{Cdc} 42$ variant 2 was observed in the miR-107 mimic-treated cells as compared to the NC-treated cells (Fig. 9B).

Enforced expression of miR-107 results in decreased expression of Cdc42 at the protein level. To verify that miR-107 acts as a Cdc42 suppressor, KYSE-410 cells were transfected with $100 \mathrm{nM}$ miR-107 and the NC. The relative expression of Cdc 42 protein was calculated as band intensity of $\mathrm{Cdc} 42 /$ band intensity of GAPDH. Densitometry analysis showed that at $48 \mathrm{~h}$ post-transfection, the overexpression of miR-107 decreased the $\mathrm{Cdc} 42$ protein level by $45.45 \%(\mathrm{P}=0.004)$ as compared to the NC (Fig. 9C and D). 
miR-107 targets Cdc42-3'UTR directly. Three sites in Cdc42 variant 1 and variant 2 were predicted to be the potential target sites of miR-107 by RNAhybrid software. Comparing the human sequence for interspecies homology, we found that, out of these three sites, two were conserved across species such as the mouse, rat, dog and chicken (Fig. 2C).

To further examine whether, $\mathrm{Cdc} 42$ is a direct target of miR-107, we cloned the 3'UTR of Cdc42 variants into the pMIR-REPORT vector. Co-transfection of miR-107 and pMIR-Cdc42-3'UTR-Var1 in the HEK293T cells resulted in $35.41 \%(\mathrm{P}=0.0154)$ decrease in the luciferase activity as compared to the NC (Fig. 9E). Co-transfection of miR-107 and pMIR-Cdc42-3'UTR-Var2 in HEK293T cells resulted in decreased luciferase activity by $28.688 \%(\mathrm{P}=0.0001)$ as compared to the NC-treated cells (Fig. 9E). CDK6 3'UTR was used as a positive control and co-transfection of miR-107 and pMIR-CDK6 3'UTR in HEK293T cells resulted in decreased luciferase activity by $48.4 \%(\mathrm{P}=0.0238)$ as compared to the NC-treated cells (Fig. 9F).

\section{Discussion}

Understanding the precise molecular mechanism underlying esophageal tumorigenesis is imperative for better management of this disease. In the present study, we unraveled the tumor suppressor role of miR-107 in esophageal carcinogenesis and further validated one of its newly identified targets i.e. Cdc42.

miR-107, a member of the miR-15/107 superfamily, has been shown to be downregulated in glioma, gastric cancer, pancreatic cancer, NSCLS and cervical cancer $(5-7,9,12)$. We previously showed miR-107 to be significantly $(\mathrm{P}=0.004)$ downregulated in $72 \%$ of esophageal cancer tissues as compared to the matched distant non-malignant tissues (21). Moreover, increasing evidence suggests a tumor-suppressor role for miR-107. It has been implicated in the regulation of cell proliferation, cell cycle arrest, migration and invasion in multiple cancers $(5,6,9,16)$. Mechanistic studies revealed that miR-107 functions as a tumor-suppressor miRNA by targeting CDK6, CDK8, let-7, CDK5R1/p35, protein kinase C $\varepsilon$ and MCL1 in various cancers $(4,5,12,15,16,18)$. Notably, overexpression of miR-107 slightly delayed c-Myc induced liver tumor formation (22) and induced cell cycle arrest at the G2/M phase thereby retarding tumor growth in nude mice (10). Our results are in concordance with the above mentioned studies suggesting a similar function of miR-107 in EC. However, our findings are in contradiction to the observations of Martello et al (23) wherein overexpression of miR-107 in MCF10A mammary epithelial cells promoted epithelial-to-mesenchymal transition resulting in a highly metastatic phenotype thorough modulation of Dicer1. In line with this report, knockdown of miR-107 lead to an increase in Dicer1 and inhibition of cell invasion and migration in gastric cancer cells (24). Taken together, these results indicate that the biology of miR-107 is complex and highly cell-type dependent. The role of miR-107 in esophageal carcinogenesis is still elusive, thus, warranting further investigation.

The above-mentioned facts thus point towards a need for in-depth functional analysis of miR-107 in ESCC to shed light on its role in tumorigenesis. Therefore, to characterize the functional importance of miR-107 in ESCC tumorigenesis, we examined the effect of miR-107 on the proliferation of
KYSE-410 cells. We observed that overexpression of miR-107 significantly suppressed the proliferation of KYSE-410 cells at $72 \mathrm{~h}$ post transfection.

Cell cycle analysis revealed that the overexpression of miR-107 in ESCC cells significantly induced cell cycle arrest at the G0/G1 phase thereby contributing to suppression of proliferation as observed by MTT assay. The anti-proliferative role of miR-107 observed herein is consistent with the previously suggested growth inhibitory function of miR-107 in gastric cancer cells and lung carcinoma $(6,9)$. Its downregulation by c-Myc has been shown to cause G2/M cell cycle progression by activating long non-coding RNA H19 in NSCLC cells (25). In line to these reports, Chen et al (5) showed that p53-induced miR-107 inhibited proliferation and arrested the cell cycle at the G0/G1 phase in glioma cells, supporting its tumorsuppressor role. Moreover, it targets CDK6 and induces cell cycle G1 arrest thereby inhibiting invasion in gastric cancer cells (6) and NSCLS (9).

Most of the cancer deaths occur due to metastasis rather than the original tumor; therefore, inhibiting cancer cell migration is an important aspect of cancer therapy and management. Previous studies have shown that miR-107 reduced cell migration and invasion, possibly through CDK-8 (26) and CDK5R1 (16) in breast cancer cells and neuroblastoma, respectively. Stückrath et al (27) showed that overexpression of miR-107 decreased migration and invasion of MCF-7 and MDA-MB-231 cells. It inhibited glioma cell migration and invasion by targeting CDK6 and NOTCH2 (5) and suppressed cervical cancer invasion by targeting MCL1 (4). To access the role of miR-107 in migration, we evaluated the effect of miR-107 on wound closure in an ESCC cell line using scratch assay. miR-107 treatment significantly inhibited cell migration in a time-dependent manner reducing the wound closure to only $50.41 \pm 7.23 \%$ at $72 \mathrm{~h}$ as compared to the negative control where cells had almost completely closed the wounds. Further investigation by Transwell-Matrigel invasion assay demonstrated that the invasive ability of KYSE-410 cells was markedly decreased after miR-107 transfection as compared to the cells transfected with NC.

Next, we investigated the effect of miR-107 overexpression on colony formation efficiency of ESCC cells and our results indicated an inhibitory effect of miR-107 on the colony formation potential of ESCC cells. The present study thus further supports the previous findings, wherein, miR-107 treatment inhibited the colony formation efficiency of cervical cancer and HNSCC cells $(12,18)$.

To explore the molecular mechanism underlying the tumor-suppressor function of miR-107, we validated one of the bioinformatically predicted targets of miR-107. We earlier predicted Cdc42 to be one of the putative targets of miR-107 using bioinformatics tools. Moreover, expression analysis in esophageal cancer tissues carried out in our previous study revealed an inverse correlation between expression of miR-107 and the Cdc42 transcript (21). Cdc42 is a member of the Rho family of small GTPases and its activation induces key signaling pathways such as cytoskeletal remodeling, cell cycle progression, establishment of cell polarity, cellular transformation and cell migration $(28,29)$. Overexpression of $\mathrm{Cdc} 42$ has been reported in several types of human cancers including NSCLC, colorectal adenocarcinoma, melanoma, breast and 
testicular cancer (30-34). In ESCC its overexpression was correlated with lymph node metastasis and pathological differentiation $(35,36)$. In addition to the cell cycle, Cdc42 also regulates the cell cytoskeleton and adhesion, cell functions that are important for cell migration and invasion in several types of cancers (37). In the present study, overexpression of miR-107 in the ESCC cell line KYSE-410 resulted in significantly decreased expression of $\mathrm{Cdc} 42$ at the mRNA level in the miR-107-treated cells as compared to the NC-treated cells, suggesting that miR-107 may regulate the expression of Cdc42 at the transcriptional level. A significant decrease in expression of $\mathrm{Cdc} 42$ protein was also observed in the miR-107-treated cells as compared to the NC-treated cells. Further validation by luciferase reporter assay confirmed $\mathrm{Cdc} 42$ as a direct downstream target of miR-107. Interestingly, previous studies have reported that $\mathrm{Cdc} 42$ is involved in proliferation, cell cycle regulation and migration as well as it increases the activity of matrix metalloproteinases (MMPs). In a positive feedback loop, $\mathrm{Cdc} 42$ induces the accumulation of its upstream activator i.e. EGFR thereby contributing to cellular proliferation and transformation $(38,39)$. Additionally, Cdc42-associated tyrosine kinase 1 (ACK1), a downstream effector of $\mathrm{Cdc} 42$, was found to positively regulate Akt and other prosurvival factors thus promoting cell survival and growth (40). Tu et al (41) demonstrated that FasL activated caspase- 3 and caspase- 8 catalyzes the cleavage of Cdc42. Notably, in the same study, caspase-insensitive Cdc42 mutants provided strong antiapoptotic effects. Furthermore, under hypoxic conditions, Cdc42 indirectly phosphorylates JNK resulting in its nuclear translocation. When translocated to the nucleus, JNK binds and activates the AP-1/MMP9 axis leading to metastatic processes (42). MMPs are critical enzymes involved in degradation of basement membrane and extracellular matrix thus helping in cancer invasion and metastasis (29). Taken together, the above mentioned facts thus indicate that $\mathrm{Cdc} 42$ plays an important role in the progression of a wide array of cancers. In the present study, we demonstrated that miR-107 was involved in the regulation of proliferation, migration and cell cycle of ESCC cells. Additionally, we identified Cdc 42 as a novel direct target of miR-107 and showed that enforced expression of miR107 in ESCC cells led to reduced expression of Cdc42. However, further in-depth analysis is warranted to establish the fact that the inhibition of Cdc42 expression may be a key mechanism by which miR-107 impairs esophageal cancer cell growth.

In conclusion, our results herein, document a key tumorsuppressor role of miR-107 in esophageal carcinogenesis by inhibiting proliferation, migration and causing cell cycle arrest in ESCC cells. We further identified and validated $\mathrm{Cdc} 42$ as a direct downstream target of miR-107. Future challenges include identifying additional targets of miR-107 to further discern its function and access its applicability in the treatment of esophageal cancer.

\section{Acknowledgements}

The present study was funded by the Department of Biotechnology; Ministry of Science and Technology; Government of India (grant no. BT/PR13311/GBD/27/246/ 2009). We are thankful to the Council of Scientific and
Industrial Research for funding the fellowship to P.S. (grant no. 09/806(0021)/2011-EMR-I).

\section{References}

1. Guo Y, Chen Z, Zhang L, Zhou F, Shi S, Feng X, Li B, Meng X, Ma X, Luo M, et al: Distinctive microRNA profiles relating to patient survival in esophageal squamous cell carcinoma. Cancer Res 68: 26-33, 2008.

2. Yamakuchi M, Lotterman CD, Bao C, Hruban RH, Karim B, Mendell JT, Huso D and Lowenstein CJ: P53-induced microRNA-107 inhibits HIF-1 and tumor angiogenesis. Proc Natl Acad Sci USA 107: 6334-6339, 2010.

3. He J, Zhang W, Zhou Q, Zhao T, Song Y, Chai L and Li Y: Low-expression of microRNA-107 inhibits cell apoptosis in glioma by upregulation of SALL4. Int J Biochem Cell Biol 45: 1962-1973, 2013.

4. Zhou C, Li G, Zhou J, Han N, Liu Z and Yin J: miR-107 activates ATR/Chk1 pathway and suppress cervical cancer invasion by targeting MCL1. PLoS One 9: e111860, 2014.

5. Chen L, Zhang R, Li P, Liu Y, Qin K, Fa ZQ, Liu YJ, Ke YQ and Jiang XD: P53-induced microRNA-107 inhibits proliferation of glioma cells and down-regulates the expression of CDK6 and Notch-2. Neurosci Lett 534: 327-332, 2013.

6. Feng L, Xie Y, Zhang $\mathrm{H}$ and Wu Y: miR-107 targets cyclindependent kinase 6 expression, induces cell cycle G1 arrest and inhibits invasion in gastric cancer cells. Med Oncol 29: 856-863, 2012.

7. Lee KH, Lotterman C, Karikari C, Omura N, Feldmann G, Habbe N, Goggins MG, Mendell JT and Maitra A: Epigenetic silencing of microRNA miR-107 regulates cyclin-dependent kinase 6 expression in pancreatic cancer. Pancreatology 9: 293-301, 2009.

8. Zhong Z, Lv M and Chen J: Screening differential circular RNA expression profiles reveals the regulatory role of circTCF25miR-103a-3p/miR-107-CDK6 pathway in bladder carcinoma. Sci Rep 6: 30919, 2016.

9. Takahashi Y, Forrest A, Maeno E, Hashimoto T, Daub CO and Yasuda J: MiR-107 and MiR-185 can induce cell cycle arrest in human non small cell lung cancer cell lines. PLoS One 4: e6677, 2009.

10. Song N, Ma X, Li H, Zhang Y, Wang X, Zhou P, Zhang X: microRNA-107 functions as a candidate tumor suppressor gene in renal clear cell carcinoma involving multiple genes. Urol Oncol 33: 205.e1-205.e11, 2015.

11. Xia H, Li Y and Lv X: MicroRNA-107 inhibits tumor growth and metastasis by targeting the BDNF-mediated PI3K/AKT pathway in human non-small cell lung cancer. Int J Oncol 49: 1325-1333, 2016.

12. Che LF, Shao SF and Wang LX: Downregulation of CCR5 inhibits the proliferation and invasion of cervical cancer cells and is regulated by microRNA-107. Exp Ther Med 11: 503-509, 2016.

13. Wang WX, Kyprianou N, Wang X and Nelson PT: Dysregulation of the mitogen granulin in human cancer through the miR-15/107 microRNA gene group. Cancer Res 70: 9137-9142, 2010.

14. Song YQ, Ma XH, Ma GL, Lin B, Liu C, Deng QJ and Lv WP: MicroRNA-107 promotes proliferation of gastric cancer cells by targeting cyclin dependent kinase 8. Diagn Pathol 9: 164, 2014.

15. Chen PS, Su JL, Cha ST, Tarn WY, Wang MY, Hsu HC, Lin MT, Chu CY, Hua KT, Chen CN, et al: miR-107 promotes tumor progression by targeting the let-7 microRNA in mice and humans. J Clin Invest 121: 3442-3455, 2011.

16. Moncini S, Salvi A, Zuccotti P, Viero G, Quattrone A, Barlati S, De Petro G, Venturin M and Riva P: The role of miR-103 and miR-107 in regulation of CDK5R1 expression and in cellular migration. PLoS One 6: e20038, 2011.

17. Zhang Z, Zhang L, Yin ZY, Fan XL, Hu B, Wang LQ and Zhang D: miR-107 regulates cisplatin chemosensitivity of A549 non-small cell lung cancer cell line by targeting cyclin dependent kinase 8. Int J Clin Exp Pathol 7: 7236-7241, 2014.

18. Datta J, Smith A, Lang JC, Islam M, Dutt D, Teknos TN and Pan Q: microRNA-107 functions as a candidate tumor-suppressor gene in head and neck squamous cell carcinoma by downregulation of protein kinase CE. Oncogene 31: 4045-4053, 2012.

19. Piao L, Zhang M, Datta J, Xie X, Su T, Li H, Teknos TN and Pan Q: Lipid-based nanoparticle delivery of Pre-miR-107 inhibits the tumorigenicity of head and neck squamous cell carcinoma. Mol Ther 20: 1261-1269, 2012. 
20. Zhang M, Wang X, Li W and Cui Y: miR-107 and miR-25 simultaneously target LATS2 and regulate proliferation and invasion of gastric adenocarcinoma (GAC) cells. Biochem Biophys Res Commun 460: 806-812, 2015.

21. Sharma P, Saraya A, Gupta P and Sharma R: Decreased levels of circulating and tissue miR-107 in human esophageal cancer. Biomarkers 18: 322-330, 2013.

22. Tao J, Ji J, Li X, Ding N, Wu H, Liu Y, Wang XW, Calvisi DF, Song $G$ and Chen $X$ : Distinct anti-oncogenic effect of various microRNAs in different mouse models of liver cancer. Oncotarget 6: 6977-6988, 2015.

23. Martello G, Rosato A, Ferrari F, Manfrin A, Cordenonsi M Dupont S, Enzo E, Guzzardo V, Rondina M, Spruce T, et al: A microRNA targeting Dicer for metastasis control. Cell 141: 1195-1207, 2010.

24. Li X, Zhang Y, Shi Y, Dong G, Liang J, Han Y, Wang X, Zhao Q, Ding J, Wu K, et al: MicroRNA-107, an oncogene microRNA that regulates tumour invasion and metastasis by targeting DICER1 in gastric cancer. J Cell Mol Med 15: 1887-1895, 2011.

25. Cui J, Mo J, Luo M, Yu Q, Zhou S, Li T, Zhang Y and Luo W: c-Myc-activated long non-coding RNA H19 downregulates miR-107 and promotes cell cycle progression of non-small cell lung cancer. Int J Clin Exp Pathol 8: 12400-12409, 2015.

26. Li XY, Luo QF, Wei CK, Li DF, Li J and Fang L: MiRNA-107 inhibits proliferation and migration by targeting CDK8 in breast cancer. Int J Clin Exp Med 7: 32-40, 2014.

27. Stückrath I, Rack B, Janni W, Jäger B, Pantel K and Schwarzenbach H: Aberrant plasma levels of circulating miR-16, miR-107, miR-130a and miR-146a are associated with lymph node metastasis and receptor status of breast cancer patients. Oncotarget 6: 13387-13401, 2015.

28. Orgaz JL, Herraiz C and Sanz-Moreno V: Rho GTPases modulate malignant transformation of tumor cells. Small GTPases 5: e29019, 2014.

29. Stengel $\mathrm{K}$ and Zheng Y: Cdc42 in oncogenic transformation, invasion, and tumorigenesis. Cell Signal 23: 1415-1423, 2011.

30. Liu Y, Wang Y, Zhang Y, Miao Y, Zhao Y, Zhang PX, Jiang GY, Zhang JY, Han Y, Lin XY, et al: Abnormal expression of p120-catenin, E-cadherin, and small GTPases is significantly associated with malignant phenotype of human lung cancer. Lung Cancer 63: 375-382, 2009.

31. Gómez Del Pulgar T, Valdés-Mora F, Bandrés E, PérezPalacios R, Espina C, Cejas P, García-Cabezas MA, Nistal M, Casado E, González-Barón M, et al: Cdc42 is highly expressed in colorectal adenocarcinoma and downregulates ID4 through an epigenetic mechanism. Int J Oncol 33: 185-193, 2008.
32. Tucci MG, Lucarini G, Brancorsini D, Zizzi A, Pugnaloni A Giacchetti A, Ricotti $G$ and Biagini G: Involvement of E-cadherin, beta-catenin, Cdc42 and CXCR4 in the progression and prognosis of cutaneous melanoma. Br J Dermatol 157: 1212-1216, 2007

33. Fritz G, Brachetti C, Bahlmann F, Schmidt M and Kaina B: Rho GTPases in human breast tumours: Expression and mutation analyses and correlation with clinical parameters. Br J Cancer 87: 635-644, 2002.

34. Kamai T, Yamanishi T, Shirataki H, Takagi K, Asami H, Ito Y and Yoshida K: Overexpression of RhoA, Rac1, and Cdc42 GTPases is associated with progression in testicular cancer. Clin Cancer Res 10: 4799-4805, 2004.

35. Feng JG, Liu Q, Qin X, Geng YH, Zheng ST, Liu T, Sheyhidin I and Lu XM: Clinicopathological pattern and Annexin A2 and Cdc42 status in patients presenting with differentiation and lymph node metastasis of esophageal squamous cell carcinomas. Mol Biol Rep 39: 1267-1274, 2012.

36. Liu Z, Feng JG, Tuersun A, Liu T, Liu H, Liu Q, Zheng ST, Huang CG, Lv GD, Sheyhidin I, et al: Proteomic identification of differentially-expressed proteins in esophageal cancer in three ethnic groups in Xinjiang. Mol Biol Rep 38: 3261-3269, 2011.

37. Ridley AJ: Rho GTPase signalling in cell migration. Curr Opin Cell Biol 36: 103-112, 2015.

38. Wang XY, Gan MX, Li Y,Zhan WH, Han TY, Han XJ, Cheng JQ and Wang JB: Cdc42 induces EGF receptor protein accumulation and promotes EGF receptor nuclear transport and cellular transformation. FEBS Lett 589: 255-262, 2015.

39. Hirsch DS, Shen Y and Wu WJ: Growth and motility inhibition of breast cancer cells by epidermal growth factor receptor degradation is correlated with inactivation of $\mathrm{Cdc} 42$. Cancer Res 66: 3523-3530, 2006

40. Mahajan K and Mahajan NP: Shepherding AKT and androgen receptor by Ack1 tyrosine kinase. J Cell Physiol 224: 327-333, 2010.

41. Tu S and Cerione RA: Cdc42 is a substrate for caspases and influences Fas-induced apoptosis. J Biol Chem 276: 19656-19663, 2001.

42. Xiao B, Chen D, Luo S, Hao W, Jing F, Liu T, Wang S, Geng Y, $\mathrm{Li} \mathrm{L}, \mathrm{Xu} \mathrm{W}$, et al: Extracellular translationally controlled tumor protein promotes colorectal cancer invasion and metastasis through Cdc42/JNK/MMP9 signaling. Oncotarget 7: 50057-50073, 2016. 